\title{
Inter-cluster voltage balancing control of a delta connected modular multilevel cascaded converter under unbalanced grid voltage
}

\author{
Oghenewvogaga J. K. Oghorada ${ }^{1,2^{*}}$ (D, Li Zhang ${ }^{3}$, Huang Han ${ }^{4}$, Ayodele B. Esan ${ }^{1,2}$ and Mingxuan Mao ${ }^{5}$
}

\begin{abstract}
A new inter-cluster DC capacitor voltage balancing scheme for a delta connected modular multilevel cascaded converter (MMCC)-based static synchronous compensator (STATCOM) is presented. A detailed power flow analysis of applying negative sequence current (NSC) and zero-sequence current (ZSC) injection methods in addressing the issue of inter-cluster DC voltage imbalance under unbalance grid voltage is carried out. A control scheme is proposed which integrates both inter-cluster methods using a quantification factor $Q_{F}$. This is used to achieve the sharing of the inter-cluster active power between the NSC and ZSC injection methods. An accurate method of determining the quantification factor is also presented. The proposed method offers better sub-module DC capacitor voltage balancing and prevents converter overcurrent. The influence of unbalanced grid voltage on the delta connected MMCC-based STATCOM rating using this integrated cluster balancing technique is investigated. The control scheme is verified with a $5 \mathrm{kV} 1.2 \mathrm{MVA}$ MMCC-STATCOM using 3-level bridge sub-modules, and the results show the advantages of the proposed method over other intercluster methods.
\end{abstract}

Keywords: Low voltage ride through (LVRT), Single delta bridge converter (SDBC), Static synchronous compensator (STATCOM), Quantification factor

\footnotetext{
* Correspondence: oghorada.oghenewvogaga@lmu.edu.ng

'SDG-7, Affordable and Clean Energy Research Group, Landmark University,

Omu-Aran, Nigeria

${ }^{2}$ Department of Electrical and Information Engineering, Landmark University,

Omu-Aran, Nigeria

Full list of author information is available at the end of the article
}

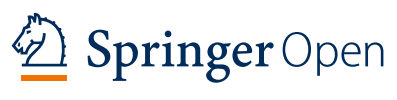

(c) The Author(s). 2021 Open Access This article is licensed under a Creative Commons Attribution 4.0 International License, which permits use, sharing, adaptation, distribution and reproduction in any medium or format, as long as you give appropriate credit to the original author(s) and the source, provide a link to the Creative Commons licence, and indicate if changes were made. The images or other third party material in this article are included in the article's Creative Commons licence, unless indicated otherwise in a credit line to the material. If material is not included in the article's Creative Commons licence and your intended use is not permitted by statutory regulation or exceeds the permitted use, you will need to obtain permission directly from the copyright holder. To view a copy of this licence, visit http://creativecommons.org/licenses/by/4.0/. 


\section{Introduction}

Grid voltage unbalance can be caused by remote faults, uneven distribution of loads such as single-phase traction drives, open wye and delta transformer banks, asymmetric transmission impedances, and so on [1]. The increasing connection of renewable source generators to the utility network exacerbates the situation because of the use of power electronic converters for grid interface and the unpredictable power generation [2]. As a consequence, all grid-tied power electronic converters are required to operate under normal and abnormal grid voltage conditions, and support the grid voltage during transient grid faults.

The modular multilevel-cascaded converter (MMCC) is attractive for medium and high voltage applications for a battery energy storage system (BESS), reactive power compensation and harmonic mitigation of a power system network [3-8]. The modular structure of this converter offers the merits of scalability, i.e. scaling up to any desired voltage level, thus eliminating the use of step-up transformers. This also helps achieve good waveform quality with low total harmonic distortion of the output voltage while only using low switching frequency leading to reduced power losses $[8,9]$.

MMCC-based STATCOM has been studied to adequately provide reactive power support to the grid under balanced conditions $[4,10]$. However, under an unbalanced grid voltage condition, it faces a challenge of active power imbalance across the converter phases [11, 12]. This unequal converter phase active power leads to inter-cluster voltage imbalance and causes sub-module DC capacitor voltage imbalance. If this inter-cluster voltage imbalance is not properly managed, distorted currents are injected into the grid via the MMCC-STAT COM. In addition, excessive drift of sub-module capacitor voltages may overstress the MMCC semiconductor switches and potentially damage the devices [13].

In [14-17], inter-cluster DC capacitor voltage balancing is achieved under an unbalanced load condition by injecting a zero-sequence current (ZSC) to circulate the three phases of the single delta bridge converter (SDBC). However, this injection method can lead to currents exceeding their rated limit and damaging converter switches. The use of a negative sequence current (NSC) injection method has not been analyzed and applied to this topology. In addition, the influence of zero sequence current and negative sequence current injection techniques on the voltage and current rating requirements of the delta connected MMCC STATCOM under grid voltage fault conditions has not been investigated.

This paper proposes a new control scheme for phasecluster voltage imbalance and overcurrent of deltaconnected MMCC-STATCOM operating under unbalanced voltage conditions. Different from conventional methods, the new scheme incorporates both methods to overcome the overcurrent problem. In applying this scheme, a quantification factor $Q_{F}$ is determined based on the maximum allowable converter current. A detailed power flow analysis of delta-connected MMCC operating under unbalanced voltage condition is carried out, and the influence of an unbalanced voltage level on the voltage and current ratings of this configuration is investigated. The MMCC sub-module considered in this paper is the 3level $\mathrm{H}$-bridge (3 L-HB), though the scheme presented can also be applied to a 5-level flying capacitor $\mathrm{H}$-bridge $(5 \mathrm{~L}$ FC) $[16,18]$. Digital simulation test results are presented to validate the proposed method.

\section{Circuit configuration of delta MMCC-based STAT COM}

Figure 1 shows the system configuration of the deltaconnected MMCC STATCOM. Each cluster consists of $N$ three-level H-bridge (3 L-HB) sub-modules connected in series. The filter reactors are connected between the SDBC phases to handle their voltage difference between phase clusters and limit the current circulating inside the converter. The DC capacitor sub-module voltages, $V_{d c m n}$,

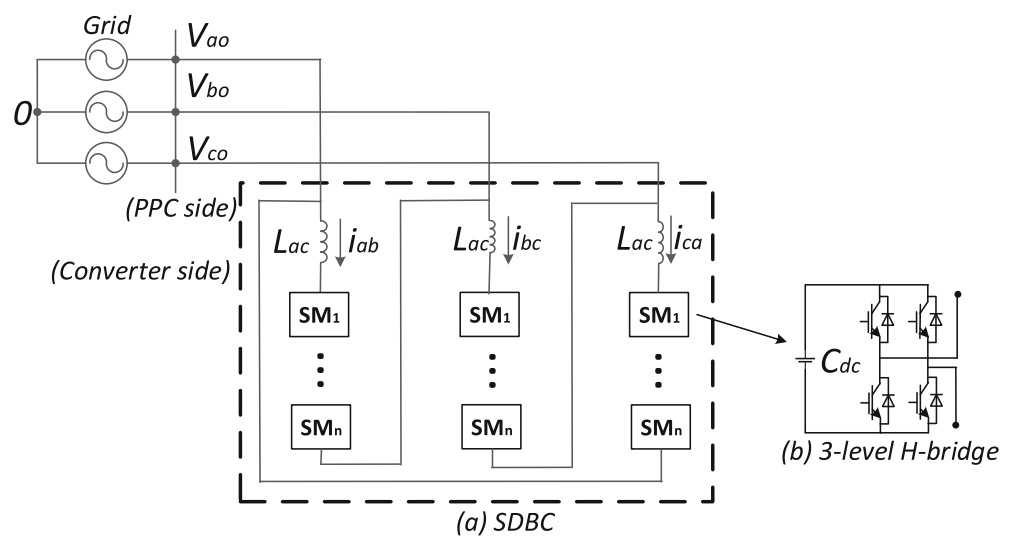

Fig. 1 Delta connected MMCC-STATCOM system 
(where $m=a b, b c, c a ; n=1,2, \ldots \mathrm{N}$ ) in each phase cluster of the MMCC need to be regulated to keep their desired values even under a grid voltage unbalanced condition. The converter voltages and currents are expressed in (1) and (2), where $k=0,1,2$. Superscripts + and -, and subscript 0 represent the positive, negative and zero sequence components. $V_{+}, V_{-}, I_{+}$and $I_{-}$represent the positive and negative sequence voltage and current magnitude. $I_{O}$ is the magnitude of the zero-sequence current. $\phi_{V_{+}}, \phi_{V-}, \phi_{I^{+}}$, and $\phi_{I-}$ are the phase angles of the positive and negative sequence voltages and currents, respectively, while $\phi_{I O}$ is the phase angle of the zero sequence current.

$$
\begin{aligned}
v_{m} & =v_{s m}^{+}+v_{s m}^{-} \\
& =\sqrt{3}\left(V_{+} \sin \left(\omega t+\phi_{V_{+}}-k \frac{2 \pi}{3}+\frac{\pi}{6}\right)+V_{-} \sin \left(-\omega t+\phi_{V_{-}}-k \frac{2 \pi}{3}+\frac{\pi}{6}\right)\right)
\end{aligned}
$$

$$
\begin{aligned}
i_{m 0} & =i_{m}^{+}+i_{m}^{-}+i_{0} \\
& =\frac{1}{\sqrt{3}}\left(I_{+} \sin \left(\omega t+\phi_{I_{+}}-k \frac{2 \pi}{3}+\frac{\pi}{6}\right)+I_{-} \sin \left(-\omega t+\phi_{I-}-k \frac{2 \pi}{3}+\frac{\pi}{6}\right)\right)
\end{aligned}
$$

\section{Delta connected MMCC-STATCOM power flow analysis}

The inter-cluster DC capacitor voltage balancing control of the delta-connected MMCC sub-modules is the main focus of this paper. The inter-cluster power flow of the system is analyzed, while multiplying (1) and (2) gives the instantaneous and average power across each phase of the delta MMCC-STATCOM. The average cluster powers are expressed as:

$$
\begin{aligned}
& P_{m}=0.5\left(P_{C m}^{++}+P_{C m}^{--}+P_{C m}^{+-}+P_{C m}^{-+}+P_{C m}^{+0}+P_{C m}^{-0}\right) \\
& P_{C m}^{++}=V_{+} I_{+} \cos \left(\phi_{V_{+}}-\phi_{I_{+}}\right) \\
& P_{C m}^{--}=V_{-} I_{-} \cos \left(\phi_{V-}-\phi_{I-}\right) \\
& P_{C m}^{+-}=-q \frac{1}{2} V_{+} I_{-} \cos \left(\phi_{V+}+\phi_{I-}\right)+r \frac{\sqrt{3}}{2} \\
& V_{+} I_{-} \sin \left(\phi_{V+}+\phi_{I-}\right) \\
& P_{C m}^{-+}=-q \frac{1}{2} V_{-} I_{+} \cos \left(\phi_{V-}+\phi_{I+}\right)+r \frac{\sqrt{3}}{2} \\
& V_{-} I_{+} \sin \left(\phi_{V-}+\phi_{I+}\right) \\
& P_{C m}^{+0}=r \frac{3}{2} V_{+} I_{0} \cos \left(\phi_{V+}-\phi_{I 0}\right)-q \frac{\sqrt{3}}{2} \\
& V_{+} I_{0} \sin \left(\phi_{V+}-\phi_{I 0}\right) \\
& P_{C m}^{-0}=-r \frac{3}{2} V_{-} I_{0} \cos \left(\phi_{V-}+\phi_{I 0}\right)+q \frac{\sqrt{3}}{2} \\
& V_{-} I_{0} \sin \left(\phi_{V-}+\phi_{I 0}\right)
\end{aligned}
$$

where $q=1,-2,1$ and $r=+1,0,-1$ for $m=a b, b c, c a$ phases, respectively.
The overall average active power $P_{T}^{++}$and $P_{T}^{--}$are solely determined by $P_{\mathrm{Cm}}{ }^{++}$and $P_{\mathrm{Cm}}{ }^{--}$while the sum of the other power terms is zero, i.e.:

$$
\begin{aligned}
& P_{T}^{++}=P_{a b}^{++}+P_{b c}^{++}+P_{c a}^{++}=\frac{3}{2} V_{+} I_{+} \cos \left(\phi_{V_{+}}-\phi_{I_{+}}\right) \\
& P_{T}^{--}=P_{a b}^{--}+P_{b c}^{--}+P_{c a}^{--}=\frac{3}{2} V_{-} I_{-} \cos \left(\phi_{V_{-}}-\phi_{I_{-}}\right) \\
& P_{T}^{+-}=P_{a b}^{+-}+P_{b c}^{+-}+P_{c a}^{+-}=0 \\
& P_{T}^{-+}=P_{a b}^{-+}+P_{b c}^{-+}+P_{c a}^{-+}=0 \\
& P_{T}^{+0}=P_{a b}^{+0}+P_{b c}^{+0}+P_{c a}^{+0}=0 \\
& P_{T}^{-0}=P_{a b}^{-0}+P_{b c}^{-0}+P_{c a}^{-0}=0
\end{aligned}
$$

The zero sequence current active power $P_{C m}{ }^{+O}$ and $P_{C m}{ }^{-O}$ do not contribute to the overall active power of the converter, as seen in (4). Thus, the zero sequence current does not influence the overall average active power control, and the overall average active power in (4) is equally provided by the individual converter phases.

The phase average active power for the delta MMCC is defined in (6).

The total average reactive power injected to the grid based on instantaneous power theory [19] is given as:

$$
\begin{aligned}
& Q_{T}^{++}=Q_{a b}^{++}+Q_{b c}^{++}+Q_{c a}^{++}=\frac{3}{2} V_{+} I_{+} \sin \left(\phi_{V_{+}}-\phi_{I_{+}}\right) \\
& Q_{T}^{--}=Q_{a b}^{--}+Q_{b c}^{--}+Q_{c a}^{--}=\frac{3}{2} V_{-} I_{-} \sin \left(\phi_{V_{-}}-\phi_{I_{-}}\right)
\end{aligned}
$$

Three possible ways of regulating the deltaconfigured MMCC are available based on (6), i.e., the positive, negative and zero sequence currents. The positive sequence current is applied in providing the total average active and reactive power control. Thus, only the negative and zero sequence currents are the control terms available for inter-cluster active power balancing control.

\section{Control scheme}

The block diagram of the MMCC STATCOM control is shown in Fig. 2. The converter control is divided into three sections of overall power control, inter-cluster average active power control and individual control. The overall controller regulates the total average active and reactive power requirements of the converter by controlling the overall DC capacitor voltages of the delta-configured MMCC and the positive sequence currents $\left(I_{+} \cos \phi_{I_{+}}, I_{+} \sin \phi_{I_{+}}\right)$, while the negative and zero sequence currents are the control terms that influence the regulation of the inter-cluster average power controller. 


$$
\begin{aligned}
& {\left[\begin{array}{l}
P_{C a b}^{+-} \\
P_{C b c}^{+-} \\
P_{C c a}^{+-}
\end{array}\right]=\frac{1}{2}\left[\begin{array}{cc}
0.5\left(-V_{+} \cos \phi_{V_{+}}+\sqrt{3} V_{+} \sin \phi_{V_{+}}\right) & 0.5\left(V_{+} \sin \phi_{V_{+}}+\sqrt{3} V_{+} \cos \phi_{V_{+}}\right) \\
V_{+} \cos \phi_{V_{+}} & -V_{+} \sin \phi_{V_{+}} \\
0.5\left(-V_{+} \cos \phi_{V_{+}}-\sqrt{3} V_{+} \sin \phi_{V_{+}}\right) & 0.5\left(V_{+} \sin \phi_{V_{+}}-\sqrt{3} V_{+} \cos \phi_{V_{+}}\right)
\end{array}\right]\left[\begin{array}{c}
I_{-} \cos \phi_{I_{-}} \\
I_{-} \sin \phi_{I_{-}}
\end{array}\right]} \\
& {\left[\begin{array}{c}
P_{C a b}^{-+} \\
P_{C b c}^{-+} \\
P_{C c a}^{-+}
\end{array}\right]=\frac{1}{2}\left[\begin{array}{cc}
0.5\left(-V_{-} \cos \phi_{V_{-}}+\sqrt{3} V_{-} \sin \phi_{V_{-}}\right) & 0.5\left(V_{-} \sin \phi_{V_{-}}+\sqrt{3} V_{-} \cos \phi_{V_{-}}\right) \\
V_{-} \cos \phi_{V_{-}} & -V_{-} \sin \phi_{V_{-}} \\
0.5\left(-V_{-} \cos \phi_{V_{-}}-\sqrt{3} V_{-} \sin \phi_{V_{-}}\right) & 0.5\left(V_{-} \sin \phi_{V_{-}}-\sqrt{3} V_{-} \cos \phi_{V_{-}}\right)
\end{array}\right]\left[\begin{array}{c}
I_{+} \cos \phi_{I_{+}} \\
I_{+} \sin \phi_{I_{+}}
\end{array}\right]}
\end{aligned}
$$

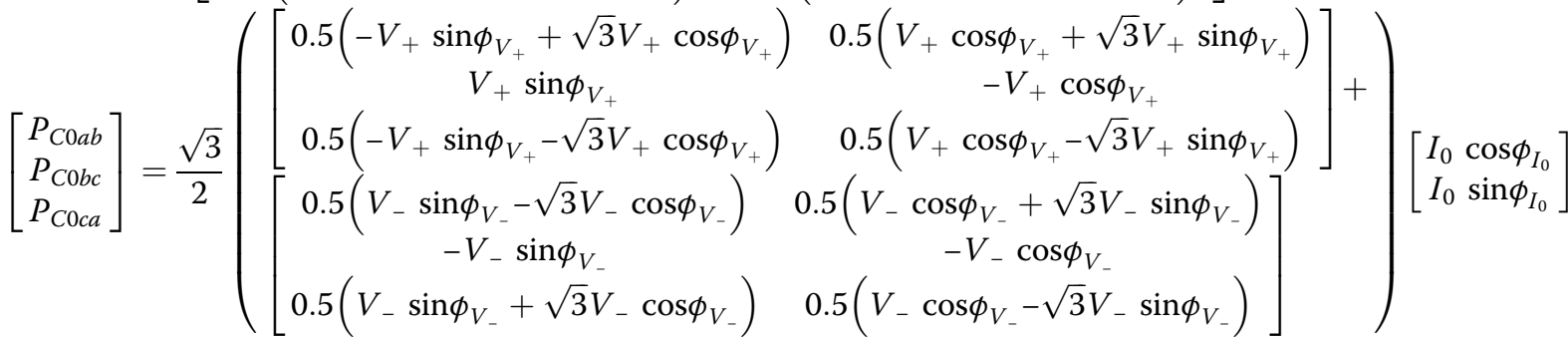

\subsection{Overall average active and reactive power control}

This controller is used to provide the active power required to compensate for power losses and maintain the MMCCSTATCOM overall DC capacitor voltages to their required values, while controlling the reactive power to be injected by the converter. This active power required by the DC capacitors is determined through a PI regulator as shown in Fig. 3. The direct component of the positive sequence current is:

$$
I_{d}^{+*}=\left(K_{p \_d c}+\frac{K_{i \_d c}}{s}\right)\left(V_{d c}^{*}-V_{d c \_a v g}\right)
$$

where $k_{p_{-} d c}$ and $k_{i_{-} d c}$ are the controller proportional and integral gain constants, and $V_{d c}{ }^{*}$ and $V_{d c \text { avg }}$ are the reference and average values of all the sub-module voltages, respectively.

The reactive current applied in the regulation of average reactive power injection is given as:

$$
I_{q}^{+*}=\frac{2 Q_{r e f}}{3 V_{d}^{+}}
$$

Where $V_{d}^{+}$and $Q_{\text {ref }}$ are the direct component of the positive sequence voltage and the reactive power reference, respectively. To prevent excessive injection of converter current under a grid unbalanced fault condition, a fixed reactive current is applied.

\subsection{Inter-cluster average active power balancing control}

The unbalanced average active phase power of the MMCC in an unbalanced grid voltage condition results in unequal

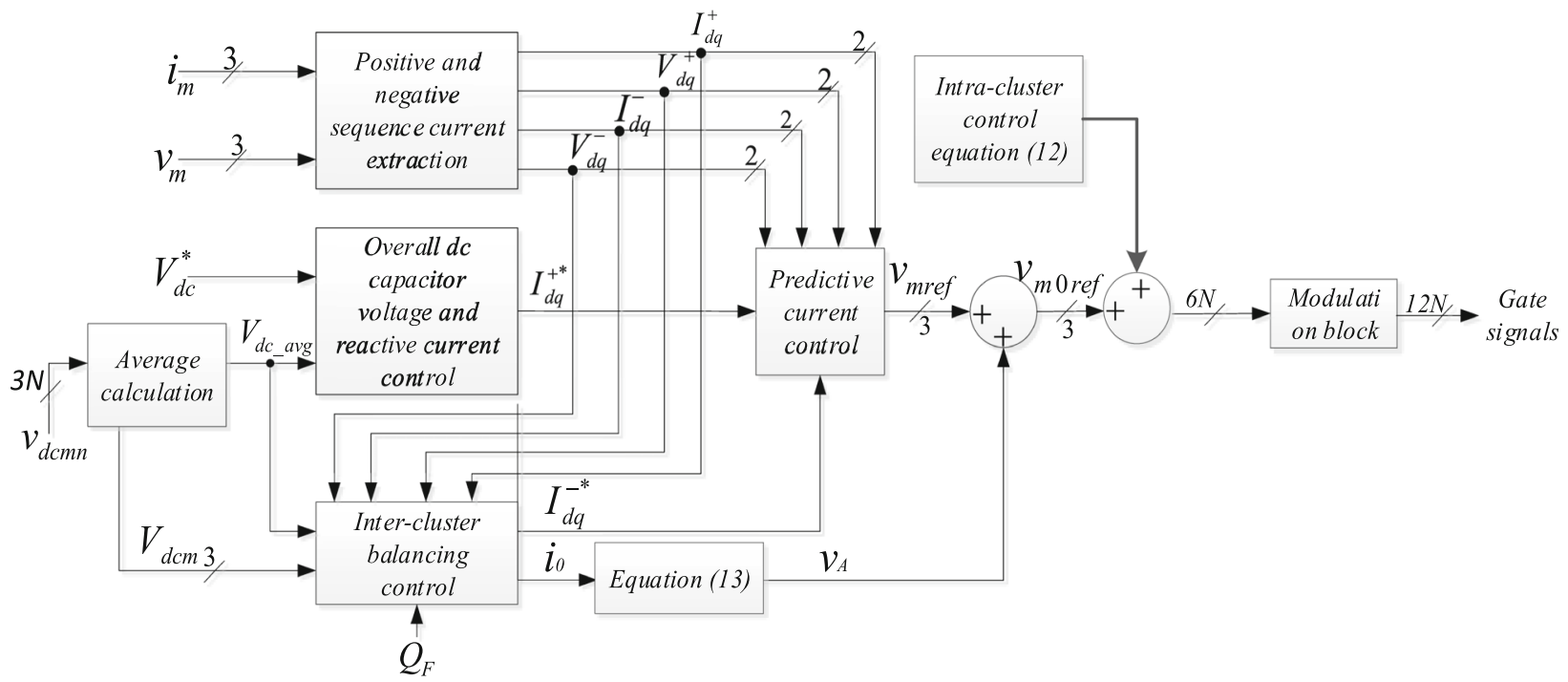

Fig. 2 Control block diagram of MMCC-STATCOM under unbalanced voltage condition 


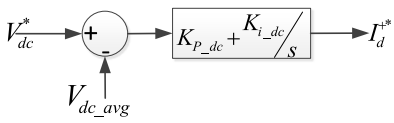

Fig. 3 Overall dc capacitor voltage control

inter-phase sub-module capacitor voltages. The cluster average active power of the converter is given as:

$$
P_{C m}=P_{C m}^{+-}+P_{C m}^{-+}+P_{C m}^{0}
$$

From (8), the average cluster active power comprises positive, negative and zero sequence current components. As the overall average active and reactive power control uses the positive sequence current, the two remaining control freedoms of negative and zero sequence currents are thus employed to regulate the inter-cluster control. A quantification factor $Q_{F}$ is used to harness the two methods in controlling the average active cluster power. This is done by effectively sharing the inter-cluster power between $P_{C m}{ }^{-+}$and $P_{C m}{ }^{o}$ methods. The 3-phase cluster power is transformed into an $\alpha-\beta$ form as:

$$
\begin{aligned}
& {\left[\begin{array}{l}
P_{C \alpha}^{+-*} \\
P_{C \beta}^{+-*}
\end{array}\right]=\left[\begin{array}{ccc}
1 & -\frac{1}{2} & -\frac{1}{2} \\
0 & -\frac{\sqrt{3}}{2} & \frac{\sqrt{3}}{2}
\end{array}\right]\left[\begin{array}{l}
P_{C a b}^{+-*} \\
P_{C b c}^{+-*} \\
P_{C c a}^{+-*}
\end{array}\right]} \\
& {\left[\begin{array}{l}
P_{C \alpha}^{0 *} \\
P_{C \beta}^{0 *}
\end{array}\right]=\left[\begin{array}{ccc}
1 & -\frac{1}{2} & -\frac{1}{2} \\
0 & -\frac{\sqrt{3}}{2} & \frac{\sqrt{3}}{2}
\end{array}\right]\left[\begin{array}{l}
P_{C a b}^{0 *} \\
P_{C b c}^{0 *} \\
P_{C c a}^{0 *}
\end{array}\right]}
\end{aligned}
$$

Equation (9) is further expressed using $Q_{F}$ as:

$$
\begin{aligned}
& P_{C m}^{+-*}=Q_{F}\left(P_{C m}^{*}-P_{C m}^{-+}\right) \\
& P_{C m}^{0 *}=\left(1-Q_{F}\right)\left(P_{C m}^{*}-P_{C m}^{-+}\right)
\end{aligned}
$$

where $m=\alpha, \beta$ phases.

Simplifying (10), the zero and negative sequence currents are given in (20).

The control scheme of the proposed inter-phase average active power balancing method is shown in Fig. 4. The output of the PI regulators $P_{C m}$ "is subtracted from the positive sequence current active power $P_{\mathrm{Cm}}{ }^{-+}$, and is then used along with the quantification factor in determining the appropriate values of the negative and zero sequence currents.

The active power across each sub-module is regulated using the individual DC capacitor voltage controller as:

$$
V_{\text {inmn }}=\left(k_{p \_ \text {in }}+\frac{k_{i \_i n}}{s}\right)\left(V_{d c m}-V_{d c m n}\right)
$$

Where $V_{\text {inmn }}$ is the individual control signal for each sub-module across a particular phase, and $k_{p \_ \text {in }}$ and $k_{i \_ \text {in }}$ are the proportional and integral gains of the individual DC capacitor voltage controller. As illustrated in Fig. 2, the negative sequence current is fed into the current controller to synthesize the converter reference voltage. The zero sequence current calculated from Fig. 4 is converted into a voltage command $V_{A}$ through a proportional controller as:

$$
V_{A}=K_{i 0}\left(I_{0} \sin \left(\omega t+\phi_{0}\right)-\frac{1}{3}\left(i_{a b}+i_{b c}+i_{c a}\right)\right)
$$

This voltage command is added to the output of the predictive current controller $v_{\text {mref }}$ to form the new converter voltage reference $v_{\text {moref }}$, which is applied to phaseshifted PWM (PS-PWM) [20-22] to generate the converter gate signals.

\subsection{Quantification factor determination}

The value of the quantification factor $Q_{F}$ is determined by ensuring that the converter-rated current is not exceeded and sub-module capacitor voltage deviations are within $\pm 10 \%$ of their rated values. Among the two inter-cluster balancing methods, the zerosequence current method is superior to the negative sequence current technique in the determination of the $Q_{F}$ value. This is because injecting negative sequence current into the grid in attaining inter-cluster voltage balancing disrupts the improvement of power quality.

The zero sequence current method is solely used to achieve inter-cluster control if the maximum

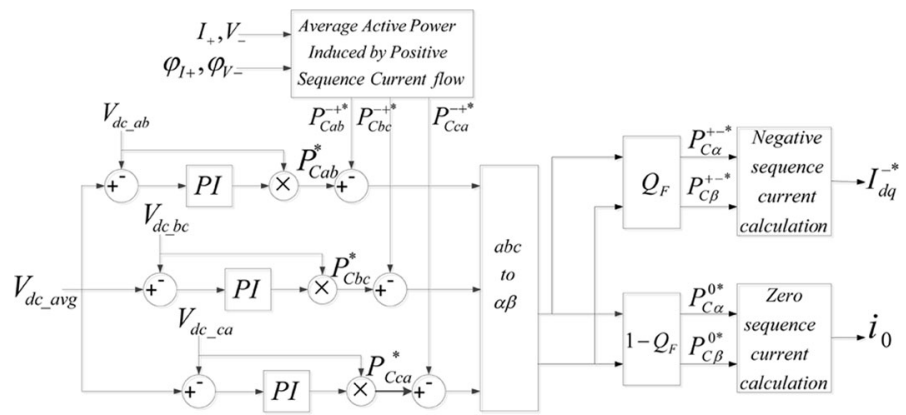

Fig. 4 Inter-cluster balancing control using quantification factor for sharing 
converter current $I_{\max }$ is less than or equal to the converter-rated current $I_{\text {Rated }}$, i.e.:

$$
\begin{aligned}
& Q_{F}=0 \text { if } I_{\max } \leq I_{\text {Rated }} \\
& I_{\max }=\max \left(i_{a b}, i_{b c}, i_{c a}\right)
\end{aligned}
$$

Where $i_{a b}, i_{b c}, i_{c a}$ are the magnitudes of the threephase converter phase currents.

For conditions when the maximum converter phase current may be higher than the rated current (i.e. $\left.I_{\text {max }}>I_{\text {Rated }}\right)$, to ensure overcurrent management, a new value of $Q_{F}$ is determined by equating the maximum current through the delta-configured MMCC as given in (14). The quantification factor $Q_{F}$ is determined by equating the magnitude of the current components as:

$$
Q_{F}=\frac{V_{+}\left[\left(V_{+}^{2}-V_{-}^{2}\right)\left(2 I_{\max }-\sqrt{2} I_{+}\right)-\sqrt{3} Z\right]}{-\sqrt{3} V_{+} Z+2 \sqrt{2}\left(V_{+}^{2}-V_{-}^{2}\right) \sqrt{\left(P_{C \alpha}^{*}-P_{C \alpha}^{+}\right)^{2}+\left(P_{C \beta}^{*}-P_{C \beta}^{-+}\right)^{2}}}
$$

Where

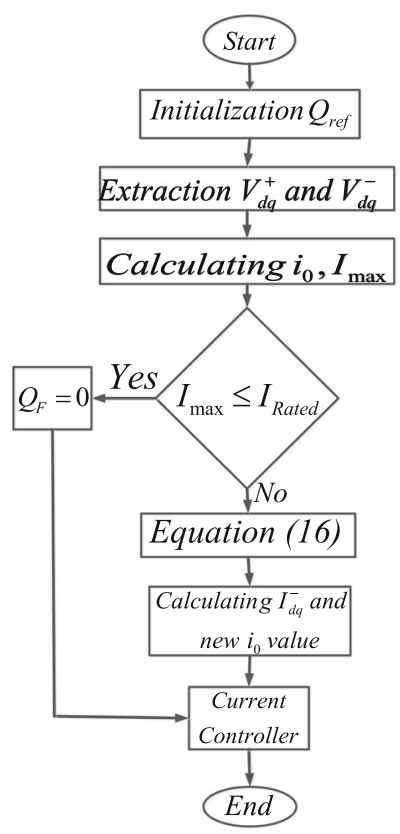

Fig. 5 Flowchart for quantification factor determination

$$
Z=2\left(\begin{array}{l}
\left(\begin{array}{l}
\left(V_{+}^{2}-V_{-}^{2}\right)+V_{-}\left(2 V_{+} \cos \phi_{V_{-}}-\sqrt{3}\right. \\
\left.V_{+} \sin \phi_{V_{-}}-\sqrt{3} V_{+} V_{-} \cos \phi_{V_{-}} \sin \phi_{V_{-}}\right)
\end{array}\right)\left(P_{C \alpha}^{*}-P_{C \alpha}^{-}\right)^{2} \\
+\left(\begin{array}{l}
\left(V_{+}^{2}-V_{-}^{2}\right)+V_{+} V_{-}\left(\cos \phi_{V_{-}}\right. \\
\left.+\sqrt{3} \sin \phi_{V_{-}}\right) \\
+\sqrt{3}\left(\left(V_{+}^{2}-V_{-}^{2}\right)+V_{+} V_{-} \cos \phi_{V_{-}}\right)\left(P_{C \alpha}^{*}-P_{C \alpha}^{*}-P_{C \alpha}^{+}\right) \\
\left(P_{C \beta}^{*}-P_{C \beta}^{+}\right)
\end{array}\right.
\end{array}\right)
$$

A flowchart for quantification factor $Q_{F}$ determination is shown in Fig. 5.

\section{Delta-connected MMCC ratings under unbalanced voltage conditions}

The operating range and ratings of delta MMCC are analyzed in a voltage unbalanced condition. These analyses are based on the integration of both inter-cluster balancing control methods of zero sequence and negative sequence currents using the quantification factor $Q_{F}$ in sharing the inter-cluster phase active power. This quantification factor has a value of $0 \leq Q_{F} \leq 1$. From (10), when $Q_{F}=0, P_{C m}{ }^{+}$ ${ }^{-"}=0$ and $P_{C m}{ }^{O^{*}}=P_{C m}{ }^{n}-P_{C m}{ }^{-+}$. When $Q_{F}=1, P_{C m}{ }^{+}$ - " $=P_{C m}{ }^{*}-P_{C m}{ }^{-+}$and $P_{C m}{ }^{0^{*}}=0$. For $0<Q_{F}<1$, $P_{C m}{ }^{+-"}=Q_{F} \quad\left(P_{C m}{ }^{*}-P_{C m}{ }^{-+}\right)$and $P_{C m}{ }^{{ }^{*}}=(1-$ $\left.Q_{F}\right)\left(P_{C m}{ }^{*}-P_{C m}\right.$. The degree of voltage imbalance $K_{v r}=V_{n} / V_{p}$ is used in this investigation. In determining the DC capacitor voltage $V_{d c_{-} \text {rated }}$ and current rating $I_{\text {Rated }}$, the influence of both intercluster balancing methods are considered. Equations (16)-(19) found in [14] are applied for this investigation.

$$
\begin{aligned}
& V_{d c_{-} \text {rated }}=\operatorname{Max}\left(\left|V_{m n}\right|\right) \leq N V_{d c} \\
& v_{m n}=v_{m}+\underbrace{L \frac{d i_{m}}{d t}+R i_{m}}_{V_{f}}=V_{m n} \sin \left(\omega t+\phi_{m}\right) \\
& i_{m 0}=i_{+}+i_{-}+i_{0} \\
& I_{\text {Rated }}=\operatorname{Max}\left(\left|i_{m 0}\right|\right)
\end{aligned}
$$

where $V_{d c}$ is the sub-module capacitor voltage, and $N$ is the number of sub-modules per cluster. $V_{f}$ represents the voltage drop across the converter filter, $i_{m o}$ is the cluster current, and $i_{+}, i_{-}$and $i_{O}$ are the positive, negative and zero sequence currents. $Q_{F}$ values of $0,0.5$ and 1 are applied across the MMCC-STAT COM for this analysis. For $Q_{F}=0$ and 1, only zerosequence current and negative sequence current methods are applied, respectively. While for $Q_{F}=0.5$, the zero and negative sequence current methods are shared equally. 


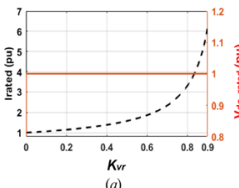

Kur
$(a)$

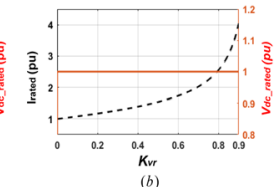

(b)

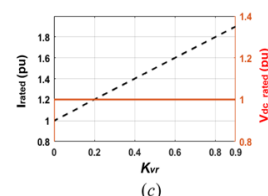

Fig. 6 DC-link cluster voltage and cluster current ratings of SDBC-STATCOM with respect to $K_{v r}$ at $\mathbf{a} Q_{F}=0, \mathbf{b} Q_{F}=0.5$ and $\mathbf{c} Q_{F}=1$ with $\varphi_{V_{-}}=0^{0}$

The influence of the quantification factor $Q_{F}$ and the degree of voltage unbalanced $\left(0 \leq Q_{F} \leq 0.9\right)$ on the current and voltage rating requirements for delta-connected STATCOM is shown in Fig. 6a-c. From Fig. 6a, the voltage and current ratings at $K_{v r}=0.8$ are $1 \mathrm{pu}$ and $3.3 \mathrm{pu}$ for $Q_{F}=0$, respectively. For $Q_{F}=0.5$ as illustrated in Fig. 6b, where $K_{v r}=0.8$, the voltage and current ratings are $1 \mathrm{pu}$ and $2.5 \mathrm{pu}$, respectively. Figure $6 \mathrm{c}$ shows that the voltage and current ratings using negative sequence current method for $Q_{F}=1$ are $1 \mathrm{pu}$ and $1.8 \mathrm{pu}$, respectively.

From this analysis, the current requirement of the zero sequence current injection method is improved by combining it with the negative sequence current technique. Thus, employing equal power sharing between both methods reduces the current rating requirement of the delta-connected MMCC-based STATCOM by $0.9 \mathrm{pu}$. These ratings have a direct implication for the switching devices and DC capacitor current handling capabilities.

\section{Results and discussion}

Table 1 MMCC power system parameters

\begin{tabular}{lll}
\hline Symbol & Quantity & Value \\
\hline Vs & Grid rms voltage & $3.535 \mathrm{kV}$ \\
S & Grid rated power & $1.2 \mathrm{MVA}$ \\
Csm & Sub-module Capacitance & $1.12 \mathrm{mF}$ \\
Lac, Rac & Filter & $8 \mathrm{mH}, 2 \Omega$ \\
Vdc & Sub-module DC voltage & $2500 \mathrm{~V}$ \\
$N$ & Number of sub-modules per phase & 4 \\
fC & Carrier frequency & $1000 \mathrm{~Hz}$ \\
fs & Sampling frequency & $10,000 \mathrm{~Hz}$ \\
\hline
\end{tabular}

Table 2 MMCC control parameters

\begin{tabular}{lll}
\hline Symbol & Quantity & Value \\
\hline$K_{p_{-} d a}, K_{i_{-} d c}$ & Overall DC voltage control & 2,20 \\
$K_{p_{-} a} K_{i_{-} c}$ & Inter-cluster control & 1,10 \\
$K_{p_{-} i n}, K_{i-i n}$ & Intra-cluster control & $0.5,5$ \\
$K_{i o}$ & Circulating current control & 35 \\
\hline
\end{tabular}

$$
\begin{aligned}
& {\left[\begin{array}{c}
I_{0} \cos \phi_{I_{0}} \\
I_{0} \sin \phi_{I_{0}}
\end{array}\right]=\frac{2}{\sqrt{3}\left(V_{+}^{2}-V_{-}^{2}\right)}\left[\begin{array}{cc}
V_{+} A+V_{-} C & -V_{+} B-V_{-} D \\
V_{+} B-V_{-} D & V_{+} A-V_{-} C
\end{array}\right]\left[\begin{array}{c}
P_{C \alpha}^{0 *} \\
P_{C \beta}^{0 *}
\end{array}\right]} \\
& I_{0}=\sqrt{\left(I_{0} \cos \phi_{I_{0}}\right)^{2}+\left(I_{0} \sin \phi_{I_{0}}\right)^{2}} \\
& \phi_{I_{0}}=\tan ^{-1}\left(\frac{I_{0} \sin \phi_{I_{0}}}{I_{0} \cos \phi_{I_{0}}}\right) \\
& {\left[\begin{array}{cc}
I_{-} \cos \phi_{I_{-}} \\
I_{-} \sin \phi_{I_{-}}
\end{array}\right]=\frac{1}{V_{+}}\left[\begin{array}{cc}
\sqrt{3} \sin \phi_{V_{+}}-\cos \phi_{V_{+}} & -\left(\sqrt{3} \cos \phi_{V_{+}}+\sin \phi_{V_{+}}\right) \\
\sqrt{3} \cos \phi_{V_{+}}+\sin \phi_{V_{+}} & \sqrt{3} \sin \phi_{V_{+}}-\cos \phi_{V_{+}}
\end{array}\right]\left[\begin{array}{c}
P_{C}^{+-*} \\
P_{C \beta}^{+*-*}
\end{array}\right]} \\
& \qquad \begin{aligned}
A & \cos \phi_{V_{+}}-\sin \phi_{V_{+}} \\
\text {where } & B=\sqrt{3} \sin \phi_{V_{+}}+\cos \phi_{V_{+}} \\
C & =\sqrt{3} \cos \phi_{V_{-}}-\sin \phi_{V_{-}} \\
D & =\sqrt{3} \sin \phi_{V_{-}}+\cos \phi_{V_{-}}
\end{aligned}
\end{aligned}
$$

Figure 1 shows the system configuration, where 4 three-level $\mathrm{H}$-bridges are cascaded in a single delta configuration. The proposed control scheme as illustrated in Fig. 2 is implemented using MATLAB / SIMULINK. The system and control parameters are shown in Tables 1 and 2, respectively. The control parameters are selected based on the cutoff frequency and phase margin of $10 \mathrm{~Hz}$ and $60^{\circ}$, respectively.

The positive sequence active and reactive current references $I_{d}^{+{ }^{+*}}$ and $I_{q}^{+{ }^{+*}}$ are synthesized by the overall active and reactive power controller. The inter-cluster balancing techniques are tested under $100 \%$ phase A voltage sag as shown in Fig. 7.

The rated STATCOM phase current is $I_{\text {rated }}=65 \mathrm{~A}$ and the converter reference DC capacitor voltage $V_{\text {dcref }}$ is fixed at $2.5 \mathrm{kV}$. To validate the effectiveness of the proposed method, the zero-sequence current and negative sequence current methods with respective quantification factors of $Q_{F}=0$ and 1 are subjected to this unbalanced condition.

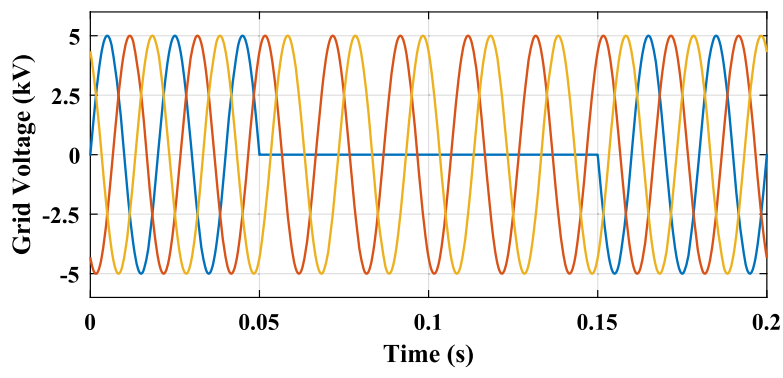

Fig. 7 Grid voltage waveform under 100\% phase A voltage sag during $100 \mathrm{~ms}\left(V_{a o}, V_{b o}, V_{c o}\right)$ 

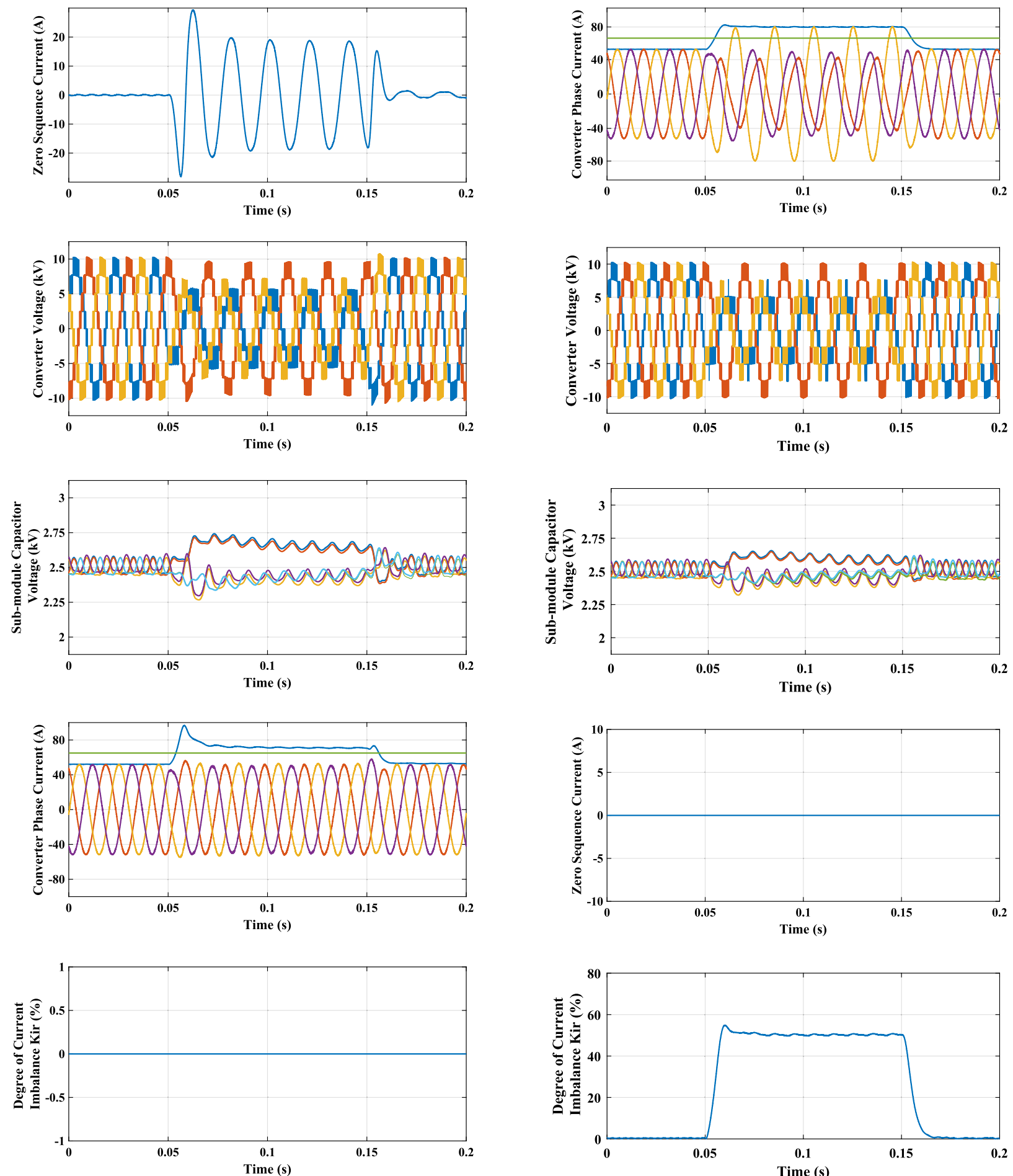

Fig. 8 Simulation result using zero sequence current injection technique. a Zero sequence current. b Converter output voltage. c Inter-cluster dc sub-module capacitor voltages. d Converter phase currents. e Degree of current imbalance

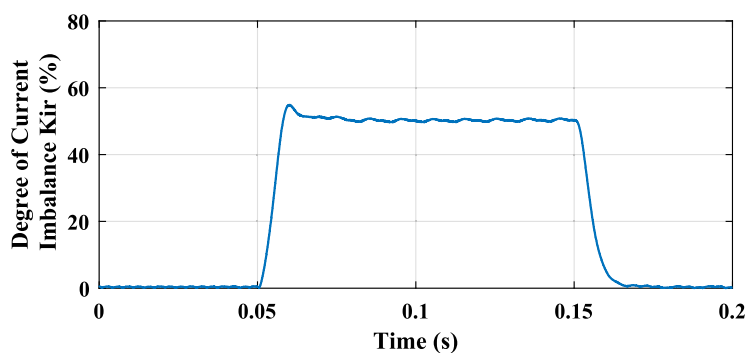

Fig. 9 Simulation result using negative sequence current injection technique. a Converter Phase currents. b Converter output voltage. c Inter-cluster dc sub-module capacitor voltages. $\mathbf{d}$ Zero sequence current. e Degree of current imbalance 

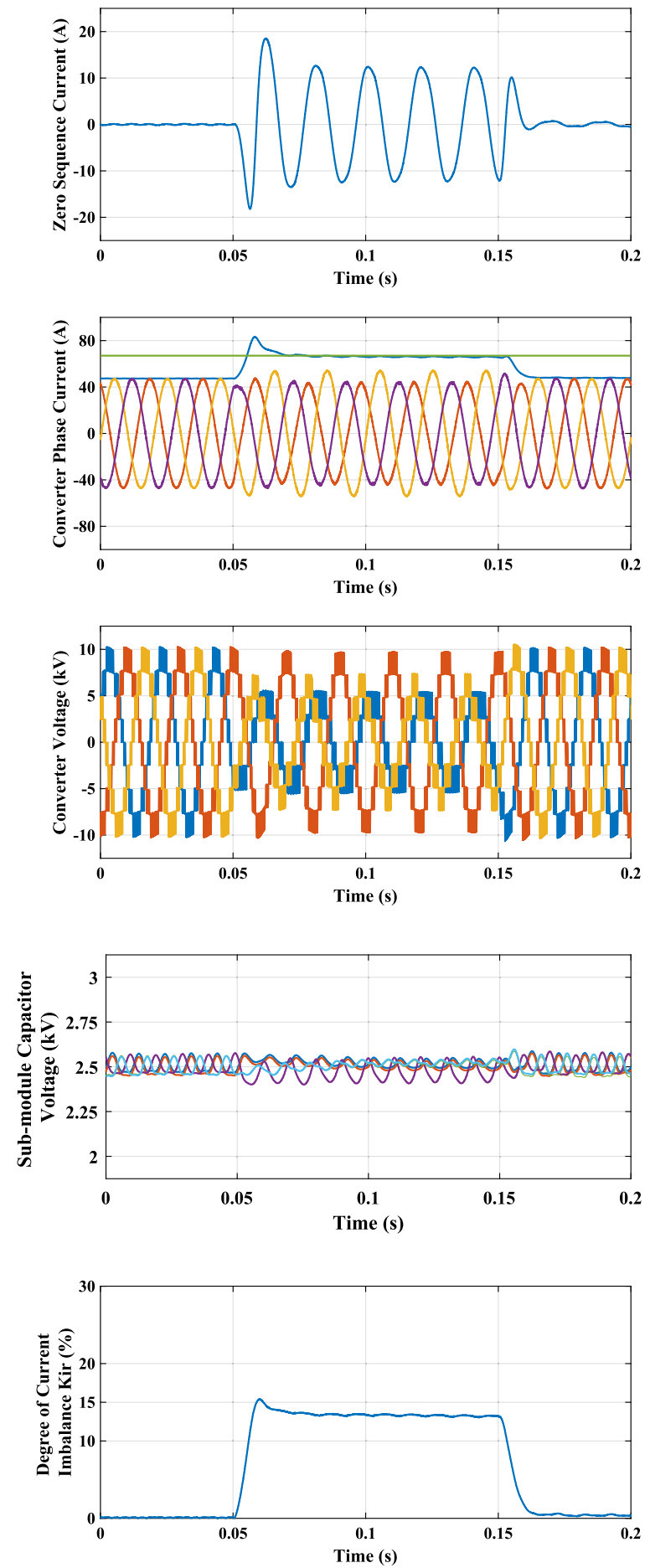

Fig. 10 Simulation result using proposed technique. a Zero sequence current. b Converter phase currents. c Converter output voltages. $\mathbf{d}$ Inter-cluster dc sub-module capacitor voltages. e Degree of current imbalance

Figure 8 shows the results of using the zero-sequence current technique for inter-cluster active power balancing control. The zero-sequence average active power is applied in compensating for the phase cluster power which generates the zero sequence current as illustrated in Fig. 8a. The MMCC-STATCOM output voltages are well-modulated as highlighted in Fig. 8b. The zerosequence current of 20A circulating in the deltaconfigured MMCC-STATCOM results in the submodule DC capacitor voltages fluctuating within $\pm 10 \%$ of their reference voltages as illustrated in Fig. 8c. The maximum total STATCOM phase current is greater than the converter current rating as illustrated in Fig. $8 \mathrm{~d}$, while Fig. 8e shows that the currents injected into the grid do not have negative sequence current.

Figure 9 shows the test results with negative sequence current inter-cluster active power balancing control. The negative sequence average active power compensates for the phase cluster power using the negative sequence current as shown in Fig. 9a, while the maximum current is $80 \mathrm{~A}$ (1.231 of $\left.I_{\text {rated }}\right)$ as indicated in Fig. 9a. This excessive current could result in semiconductor switch thermal breakdown. Figure $9 \mathrm{~b}$ shows that the converter output voltages are not over-modulated, while Fig. 9c shows that the sub-module capacitor voltages are maintained within $\pm 7 \%$ of their reference values. Figure $9 \mathrm{~d}$ shows that no zero sequence current is required with this technique. However, the degree of current imbalance injected to the grid is $50 \%$ as seen in Fig. 9e, and this could result in more imbalance in the grid.

Figure 10 shows the results of the proposed technique for the inter-cluster active power balancing control. To overcome the problems posed by zero sequence current and negative sequence current methods, the proposed method determines the quantification factor using (15) as $Q_{F}=0.381$, i.e. sharing the inter-cluster unbalanced active powers between zero-sequence current and negative sequence current in proportions of $61.9 \%$ and $38.1 \%$, respectively.

Comparing Figs. 8a and 10a, the magnitude of the zero sequence current for the proposed method is less than the value for the zero-sequence current injection technique. The maximum current injected into the grid is seen to be equal to the rated current as illustrated in Fig. 10b, and this is lower than the case of NSC and ZSC injection methods shown in Figs. 8d and 9a, respectively. Figure 10c shows that the converter output voltages are also well-modulated. The proposed method maintains the sub-module DC capacitor voltages ripple to be less than $\pm 3 \%$ as seen in Fig. 10d. Figure 10e shows that the level of current imbalance injected into the grid by the proposed method is less than with the NSC method. 
Table 3 comparison of inter-cluster balancing methods

\begin{tabular}{llll}
\hline Parameters & Proposed method & Negative sequence current & Zero sequence current \\
\hline Maximum current flowing in the converter & $65 \mathrm{~A}$ & $80 \mathrm{~A}$ & $70 \mathrm{~A}$ \\
Maximum current flowing from the converter to the grid & $55 \mathrm{~A}$ & $80 \mathrm{~A}$ & $48 \mathrm{~A}$ \\
Degree of unbalanced current injected to the grid & $13.8 \%$ & $50 \%$ & $0 \%$ \\
Switching power losses PS & 0.81 PS & PS & $0.9 P_{S}$ \\
Maximum sub-module capacitor voltage variation & $\pm 3 \%$ & $\pm 7 \%$ & $\pm 10 \%$ \\
\hline
\end{tabular}

Table 3 compares the proposed method against the other two inter-cluster techniques. The following metrics are considered:

- The maximum current flowing in the converter: this is the sum of all the current components as expressed in (18). Only the proposed method operates within the rated current of the converter while the others have higher current flowing in the converter.

- The maximum current flowing from the converter to the grid: since the zero-sequence current only flows within the converter clusters, this quantity is the sum of both positive and negative sequence grid currents. The NSC method injects a higher current to the grid than the proposed and ZSC methods.

- Degree of unbalanced current injected to the grid $\boldsymbol{K}_{\boldsymbol{i r}}$ : this is the ratio of negative sequence current to positive sequence current. The proposed method injects less unbalanced current to the grid than the NSC method, while the ZSC offers no unbalanced current to the grid.

- Switching power losses $\boldsymbol{P}_{\boldsymbol{S}}$ : this is calculated as:

$$
P_{S}=\frac{1}{T_{S}}\left(\begin{array}{l}
f_{S_{O N}}\left(i_{C}(t), T_{j_{-} T}(t)\right) * \frac{V_{C E}}{V_{C E_{-} \operatorname{Re} f}} \\
+f_{S_{\text {OFF }}}\left(i_{C}(t), T_{j_{-} T}(t)\right) * \frac{V_{C E}}{V_{C E_{-} \operatorname{Re} f}} \\
+f_{S_{\text {OFF }}}\left(i_{F}(t), T_{j_{-} D}(t)\right) * \frac{V_{F}}{V_{F_{-} \operatorname{Re} f}}
\end{array}\right)
$$

where $f_{S O N}$ and $f_{\text {SOFF }}$ are the switching energy functions for turn-on and turn-off energies. $T_{j_{-} T}$ and $T_{j_{-} D}$ are the respective junction temperatures of IGBT and diode, while $V_{C E \_R e f}, V_{F_{-} R e f}$ are the reference voltages for defining the IGBT and diode switching losses [20]. Since all the methods are subject to the same operating condition including modulation techniques, the only varying parameter is the current. Therefore, the switching power losses are simply expressed as a function of current as $P_{S}=f(i(t))$. The proposed method offers the lowest power losses of the three methods.

\section{- Maximum sub-module capacitor voltage vari-} ation: this is the ratio of the change in sub-module capacitor voltage to the reference capacitor voltage. From Table 3, the proposed method has the least variation of the three inter-cluster power balancing methods.

From the results, the proposed method is superior to the zero and negative sequence current methods.

\section{Conclusion}

The inter-cluster active power balancing control of the delta-connected STATCOM in an unbalanced voltage condition is of serious concern. This paper has proposed an inter-cluster active power balancing method to address the challenges posed by both zero sequence current and negative sequence current injection methods which result in sub-module DC capacitor voltages drift and overcurrent, respectively. The relationship between the active power flow and inter-cluster DC capacitor voltages are discussed, while the power flow analysis and the proposed method are presented in detail. The effectiveness of the proposed method is achieved by determining the optimum quantification factor $Q_{F}$ value which integrates zero sequence current and negative sequence current in the correct proportion in addressing the problems of the two methods. The influence of $Q_{F}$ as the degree of unbalanced voltage $k_{v r}$ increases on the voltage and current ratings of the delta-connected MMCC STATCOM is also investigated. The simulation results using the proposed method show that:

- the sub-module DC capacitor voltage fluctuations are maintained within $\pm 3 \%$ of the reference voltage;

- the maximum current is within the rated value;

- converter switching power losses are reduced;

- less unbalance current is injected into the grid than with the NSC method.

\section{Abbreviations}

ZSC: Zero sequence current; NSC: Negative sequence current; SDBC: Single delta bridge converter; LVRT: Low voltage ride through; STATCOM: Static synchronous compensator; MMCC: Modular multilevel cascaded converter; BESS: Battery energy storage system; 3 L-HB: 3-level H-bridge; 5 L-FC: 5-level Flying capacitor 


\section{Acknowledgements}

The authors acknowledge the Management of Landmark University for their contribution in driving quality research.

\section{Authors' contributions}

Author 1: conceived and designed the analysis, wrote the paper. Author 2: wrote the paper. Author 3: performed the analysis. Author 4: analysis tool. Author 5: performed the analysis. The author(s) read and approved the final manuscript.

\section{Funding}

No funding from any external source.

\section{Availability of data and materials}

The research was carried out using MATLAB SIMULINK.

\section{Declarations}

\section{Competing interests}

The authors declare that they have no known competing financial interests or personal relationships that could have appeared to influence the work reported in this paper.

\section{Author details}

${ }^{1}$ SDG-7, Affordable and Clean Energy Research Group, Landmark University, Omu-Aran, Nigeria. ${ }^{2}$ Department of Electrical and Information Engineering, Landmark University, Omu-Aran, Nigeria. ${ }^{3}$ School of Electronic and Electrical Engineering, University of Leeds, Leeds, UK. ${ }^{4}$ College of Engineering, Swansea University, Swansea, UK. ${ }^{5}$ School of Electrical Engineering, Chongqing University, Chongqing, China.

Received: 19 November 2020 Accepted: 15 June 2021

Published online: 23 July 2021

\section{References}

1. Oghorada, O. J. K., Nwobu, C. J., \& Zhang, L. (2016). Control of a single-star flying capacitor converter modular multi-level cascaded converter (SSFCCMMCC) STATCOM for unbalanced load compensation, (pp. 1-6).

2. Oghorada, O. J. K., \& Zhang, L. (2016). Control of a Modular Multi-level Converter STATCOM for low voltage ride-through condition. In IECON 2016 42nd Annual Conference of the IEEE Industrial Electronics Society, (pp. 36913696). IEEE.

3. Akagi, H. (2011). Classification, terminology, and application of the modular multilevel cascade converter (MMCC). IEEE Transactions on Power Electronics, 26(11), 3119-3130. https://doi.org/10.1109/TPEL.2011.2143431.

4. Sano, K., \& Takasaki, M. (2012). A transformer less DSTATCOM based on a multi-voltage cascade converter requiring no DC sources. IEEE Transactions on Power Electronics, 27(6), 2783-2795.

5. Hagiwara, M., Maeda, R., \& Akagi, H. (2011). Application of a Modular Multilevel Cascade Converter (MMCC-SDBC) to a STATCOM. IEEE Transactions on Industry Applications, 131(12), 1433-1441. https://doi.org/10.1 541/ieejias.131.1433.

6. Nwobu, C., Oghorada, O. J. K., et al. (2015). A modular multilevel flying capacitor converter-based STATCOM for reactive power control in distribution systems. In Power Electronics and Applications (EPE'15), 17th European Conference on.

7. Gultekin, B., \& Ermis, M. (2013). Cascaded multilevel converter based transmission STATCOM: system design methodology and development of a $12 \mathrm{kV} \pm 12$ MVAr power stage. IEEE Transactions on Power Electronics, 28(11), 4930-4950.

8. Akagi, H., Inoue, S., \& Yoshii, T. (2007). Control and performance of a transformer less cascade PWM STATCOM with star configuration. IEEE Transactions on Industry Applications, 43(4), 1041-1049.

9. Zhang, J., Xu, S., Din, Z., \& Hu, X. (2019). Hybrid multilevel converters: Topologies, evolutions and verifications. Energies, 12(4), 615. https://doi.org/1 0.3390/en12040615.

10. Huang, H., Oghorada, O. J. K., Zhang, L., \& Chong, B. V. P. (2017). Active harmonic current elimination and reactive power compensation using modular multilevel cascaded converter. In 2017 19th European Conference on Power Electronics and Applications (EPE'17 ECCE Europe), (p. 1). IEEE.
11. Lee, C., Wang, B. S., Chen, S. W., Chou, S. F., Huang, J. L., Cheng, P. T., Barbosa, P. (2014). Average power balancing control of a STATCOM based on the cascaded H-bridge PWM converter with star configuration. IEEE Transactions on Industry Applications, 50(6), 3893-3901. https://doi.org/10.11 09/TIA.2014.2312618.

12. Sochor, P., \& Akagi, H. (2016). Theoretical comparison in energy-balancing capability between star- and delta-configured modular multilevel cascade inverters for utility-scale photovoltaic systems. IEEE Transactions on Power Electronics, 31(3), 1980-1992. https://doi.org/10.1109/TPEL.2015.2442261.

13. Oghorada, O. J. K., \& Zhang, L. (2018). Analysis of star and delta connected modular multilevel cascaded converter-based STATCOM for load unbalanced compensation. International Journal of Electrical Power \& Energy Systems, 95, 341-352. https://doi.org/10.1016/j.jiepes.2017.08.034.

14. Oghorada, O. J. K., \& Zhang, L. (2019). Unbalanced and reactive load compensation using MMCC-based SATCOMs with third-harmonic injection. IEEE Transactions on Industrial Electronics, 66(4), 2891-2902. https://doi.org/1 $0.1109 /$ TIE.2018.2849962

15. Wu, P., Chen, H., Chang, Y., \& Cheng, P. (2017). Delta-connected cascaded Hbridge converter application in unbalanced load compensation. IEEE Transactions on Industry Applications, 53(2), 1254-1262. https://doi.org/10.11 09/TIA.2016.2633945.

16. Oghorada, O. J. K. (2017). Modular multilevel cascaded flying capacitor STAT COM for balanced and unbalanced load compensation. PhD. School of Electronic/Electrical Engineering, University of Leeds.

17. Lee, C., Chen, H., Wang, C., Wu, P., Yang, C., \& Cheng, P. (2014). A peak current limit control technique in low-voltage ride through operation of the star-connected cascaded H-bridges converter. In 2014 IEEE Energy Conversion Congress and Exposition (ECCE), Pittsburgh, PA, (pp. 505-512).

18. Oghorada, O. J. K., Zhang, L., Efika, I. B., \& Nwobu, C. J. (2018). Control of modular multilevel converters using an overlapping multi-hexagon space vector modulation scheme. IEEE Journal of Emerging and Selected Topics in Power Electronics, 7(1), 381-391.

19. Akagi, H., Watanabe, E. H., \& Aredes, M. (2017). Instantaneous power theory and applications to power conditioning. Wiley.

20. Oghorada, O. J. K., Zhang, L., Esan, B. A., \& Dickson, E. (2019). Carrier-based sinusoidal pulse-width modulation techniques for flying capacitor modular multi-level cascaded converter. Heliyon, 5(12), e03022.

21. Huang, H., Zhang, L., Oghorada, O., \& Mao, M. (2021). Analysis and control of a modular multilevel cascaded converter-based unified power flow controller. IEEE Transactions on Industry Applications, 57(3), 3202-3213. https://doi.org/10.1109/TIA.2020.3029546.

22. Oghorada, O., Zhang, L., Esan, A., Egbune, D., \& Uwagboe, J. (2020). Intercluster voltage balancing control of modular multilevel cascaded converter under unbalanced grid voltage. Journal of Modern Power Systems and Clean Energy.

\section{Submit your manuscript to a SpringerOpen ${ }^{\circ}$ journal and benefit from:}

- Convenient online submission

Rigorous peer review

- Open access: articles freely available online

High visibility within the field

- Retaining the copyright to your article

Submit your next manuscript at $\boldsymbol{\nabla}$ springeropen.com 